\title{
Intracellular Zinc Elevation Measured with a "Calcium- Specific" Indicator during Ischemia and Reperfusion in Rat Hippocampus: A Question on Calcium Overload
}

\author{
Christian J. Stork and Yang V. Li \\ Department of Biomedical Science, Program in Molecular and Cellular Biology, Ohio University, Athens, Ohio 45701
}

\begin{abstract}
Much of our current evidence concerning of the role of calcium $\left(\mathrm{Ca}^{2+}\right)$ as a second messenger comes from its interaction with fluorescent probes; however, many $\mathrm{Ca}^{2+}$ probes also have a higher affinity for another divalent cation: $\mathrm{zinc}\left(\mathrm{Zn}^{2+}\right)$. In this study, using a selective $\mathrm{Zn}^{2+}$ probe (Newport Green), we investigated the accumulation of intracellular $\mathrm{Zn}^{2+}$ transients in acute rat hippocampal slices during ischemia, simulated by oxygen and glucose deprivation (OGD). Subsequent reperfusion with glucose-containing oxygenated medium resulted in an additional increase in intracellular $\mathrm{Zn}^{2+}$. Such observations compelled us to investigate the contribution of $\mathrm{Zn}^{2+}$ to the alleged intracellular $\mathrm{Ca}^{2+}$ overload occurring in ischemia and reperfusion. Using confocal fluorescent microscopy of Calcium Green-1, a widely used $\mathrm{Ca}^{2+}$ indicator, we detected increases in fluorescence intensity during OGD and reperfusion. However, application of a $\mathrm{Zn}^{2+}$ chelator, at the peak of the fluorescence elevation (interpreted as $\mathrm{Ca}^{2+}$ overload), resulted in a significant drop in intensity, suggesting that rising $\mathrm{Zn}^{2+}$ is the primary source of the increasing Calcium Green-1 fluorescence. Finally, staining with the cell viability indicator propidium iodide revealed that $\mathrm{Zn}^{2+}$ is responsible for the ischemic neuronal cell death, because $\mathrm{Zn}^{2+}$ chelation prevented cells from sustaining ischemic damage. Current cellular models of ischemic injury center on $\mathrm{Ca}^{2+}$-mediated excitotoxicity. Our results indicate that $\mathrm{Zn}^{2+}$ elevation contributes to conventionally recognized $\mathrm{Ca}^{2+}$ overload and also suggest that the role of $\mathrm{Ca}^{2+}$ in neurotoxicity described previously using $\mathrm{Ca}^{2+}$ probes may need to be re-examined to determine whether effect previously attributed to $\mathrm{Ca}^{2+}$ could, in part, be attributable to $\mathrm{Zn}^{2+}$.
\end{abstract}

Key words: zinc; calcium; fluorescence; ischemia; nitric oxide; cell death

\section{Introduction}

The transition metal ion $\mathrm{Zn}^{2+}$, an essential cofactor for many enzymes and other proteins (Vallee and Falchuk, 1993), has recently emerged as a possible cellular messenger in physiological and cytotoxic signaling (Bossy-Wetzel et al., 2004; Frederickson et al., 2005). In the CNS, $\mathrm{Zn}^{2+}$ is important for brain development, and the maintenance of an appropriate $\mathrm{Zn}^{2+}$ concentration is critical to brain function. Moreover, exposure of neurons to excessive $\mathrm{Zn}^{2+}$ can be toxic (Yokoyama et al., 1986), inducing apoptosis at lower concentrations (Manev et al., 1997; Lobner et al., 2000) and necrosis at higher concentrations (Tonder et al., 1990; Choi and Koh, 1998). A growing body of evidence also demonstrates $\mathrm{Zn}^{2+}$ accumulation during oxygen and glucose deprivation (OGD), followed by reperfusion (Tonder et al., 1990; Koh et al., 1996; Snider et al., 2000; Lee et al., 2002; Wei et al., 2004). The $\mathrm{Zn}^{2+}$ chelating agent CaEDTA (Koh et al., 1996; Frederickson et al., 2002) and metal-binding proteins (van Lookeren

\footnotetext{
Received April 12, 2006; revised Aug. 25, 2006; accepted Aug. 25, 2006.

This work was supported in part by grants from the American Heart Association (Y.V.L.) and the National Institutes of Health (Y.V.L). We thank Klaus Himmeldirk for critical comments on the molecular modeling of fluorescent indicators and Rengarajan Balaji for review of this manuscript.

Correspondence should be addressed to Dr. Yang V. Li, Department of Biomedical Sciences, Ohio University, 346 Irvine Hall, Athens, OH 45701. E-mail: Li@oucom.ohiou.edu.

D0I:10.1523/JNEUROSCI.1588-06.2006

Copyright $\odot 2006$ Society for Neuroscience $\quad 0270-6474 / 06 / 2610430-08 \$ 15.00 / 0$
}

Campagne et al., 1999) have been demonstrated to prevent the ischemia-induced injury.

$\mathrm{Ca}^{2+}$ plays an important role in the regulation of a variety of neuronal processes including excitability, associativity, neurotransmitter release, gene transcription, cell proliferation, and synaptic plasticity (Clapham, 1995; Berridge, 1998; Verkhratsky, 2005). Many studies have implicated $\mathrm{Ca}^{2+}$ as a mediator or trigger of neuronal damage and neurotoxicity. For example, the role of excessive $\mathrm{Ca}^{2+}$ influx or $\mathrm{Ca}^{2+}$ overloading in neuronal death after ischemic insults or brain trauma has been studied extensively (Benveniste et al., 1988; Paschen, 1996; Perez Velazquez et al., 1997; Nishizawa, 2001). Nevertheless, treatments or clinical drug trials designed to alter $\mathrm{Ca}^{2+}$ influx or $\mathrm{Ca}^{2+}$ homeostasis have met with limited success in reducing the volume or severity of neuronal damage (White et al., 1996; National Institute of Neurological Disorders and Stroke, 2002).

Because much of the current knowledge about the roles of $\mathrm{Ca}^{2+}$ elevation is derived from its interaction with fluorescent indicators, the evidence for increases in intracellular $\mathrm{Zn}^{2+}$ during ischemic neural damage thereby poses a dilemma. This dilemma is particularly apparent when one considers that nearly all fluorescent $\mathrm{Ca}^{2+}$ indicators also bind $\mathrm{Zn}^{2+}$ with a high affinity (Grynkiewicz et al., 1985; Tsien and Pozzan, 1989). In essence, the elevation of intracellular $\mathrm{Zn}^{2+}$ may comprise part of, or the entirety of, conventionally measured intracellular $\mathrm{Ca}^{2+}$ signals. 
For example, although best known as an excitation wavelength ratiometric indicator for $\mathrm{Ca}^{2+}$, fura-2 is actually a 100 -fold more sensitive as an indicator for $\mathrm{Zn}^{2+}$ than $\mathrm{Ca}^{2+}$. The potential problems arising from such sensitivity of fluorescent indicators to $\mathrm{Zn}^{2+}$ and of interference by $\mathrm{Zn}^{2+}$ have been essentially ignored, attributable in part to the assumption that intracellular concentrations of $\mathrm{Zn}^{2+}$ are very low (Haugland, 2001). Here, we demonstrate that ischemia simulated by OGD, followed by reperfusion, result in an increase in $\left[\mathrm{Zn}^{2+}\right]_{\mathrm{i}}$ in global hippocampal slices. Furthermore, when a classic calcium indicator (Calcium Green-1) was used to monitor intracellular $\mathrm{Ca}^{2+}$ rises, it turned out that a significant amount of the purported $\mathrm{Ca}^{2+}$ fluorescent signal was actually caused by an elevation of $\mathrm{Zn}^{2+}$.

\section{Materials and Methods}

Preparations of brain slices and solutions. Male Sprague Dawley rats (200$250 \mathrm{~g}$ ) were anesthetized with ketamine $\mathrm{HCl}$ and decapitated; the brain was then quickly removed and submerged in ice-cold artificial CSF (ACSF). Coronal slices, $250 \mu \mathrm{m}$ in thickness, were made using a Vibratome (Series 3000 with 900R refrigeration; The Vibratome Company, St. Louis, MO). ACSF in the slicing chamber was kept ice cold and contained the following (in $\mathrm{mM}$ ): $121 \mathrm{NaCl}, 1.75 \mathrm{KCl}, 5 \mathrm{MgCl}_{2}, 1.25$ $\mathrm{KH}_{2} \mathrm{PO}_{4}, 26 \mathrm{NaHCO}_{3}$, and 10 glucose, gassed with $95 \% \mathrm{O}_{2} / 5 \% \mathrm{CO}_{2}$. After equilibrium, slices were transferred to a dye incubation chamber containing $2 \mathrm{ml}$ of ACSF used in experiments (to which $2.5 \mathrm{~mm} \mathrm{CaCl}$ was added and $\mathrm{MgCl}_{2}$ was $1.3 \mathrm{~mm}$ rather than $5 \mathrm{~mm}$ ) at $32^{\circ} \mathrm{C}$ and bubbled with $95 \% \mathrm{O}_{2} / 5 \% \mathrm{CO}_{2}$. Care was taken to minimize potential $\mathrm{Zn}^{2+}$ contamination (Martin et al., 2006). All solutions were kept in Teflon bottles, and solutions/chemicals were transferred with metal-free pipette tips or spatulas coated with polymethylpentene. The testing buffer/solution was made with puriss grade salts [Sigma (St. Louis, MO) or Fluka (Neu-Ulm, Germany)] and, in some experiments (see Fig. 3), also stripped of divalent metal ions by treatment with Chelex-100 beads (5\%; Bio-Rad, Richmond, CA).

Intracellular $\mathrm{Zn}^{2+}$ measurements. To monitor intracellular $\mathrm{Zn}^{2+}$ $\left(\left[\mathrm{Zn}^{2+}\right]_{\mathrm{i}}\right)$, hippocampal slices were loaded with $10 \mu \mathrm{M}$ Newport Green (NG) DCF diacetate (excitation $\lambda, 505 \mathrm{~nm}$; emission $\lambda, 535 \mathrm{~nm}$ ) or $10 \mu \mathrm{M}$ Calcium Green-1 AM (excitation $\lambda, 506 \mathrm{~nm}$; emission $\lambda, 531 \mathrm{~nm}$ ) in $0.05 \%$ DMSO and 0.01 Pluronic F-127 from a $20 \%$ w/v stock solution of Pluronic F-127 dissolved in DMSO. Slices were maintained in the incubation chamber for $45 \mathrm{~min}$ at $32^{\circ} \mathrm{C}$. Slices were then washed three times with ACSF and incubated for an additional $30 \mathrm{~min}$ in ACSF before imaging. All experiments were performed at $32^{\circ} \mathrm{C}$, maintained at temperature with an SC-20 in-line heater equipped with a CL-100 temperature controller (Warner Instruments, Hamden, CT) under constant perfusion $(2 \mathrm{ml} / \mathrm{min}$ ) maintained by a Peristar peristaltic pump (World Precision Instruments, Sarasota, FL) in a $35 \mathrm{~mm}$ glass-bottomed chamber (MatTek, Ashland, MA) on the stage of an inverted laser-scanning confocal microscope (Axiovert LSM510; Zeiss, Oberkochen, Germany) or a Motic inverted microscope equipped with an Olympus (Tokyo, Japan) $10 \times, 1.1$ numerical aperture lens and a CCD camera (Retiga 1300i; QImaging, Burnaby, British Columbia, Canada). The images were digitized, and analysis was performed using Zeiss imaging software or ImagePro Plus software (Media Cybernetics, Silver Spring, MD).

OGD of slices. All oxygen-glucose-deprived slice manipulations were performed in $35 \mathrm{~mm}$ glass-bottomed chambers (MatTek) where slices were fully submerged in circulated oxygen-glucose-deprived ACSF and held in position using a circular platinum wire with a nylon grid that allowed for solution exchange. All solutions were prebubbled with either $95 \% \mathrm{O}_{2} / 5 \% \mathrm{CO}_{2}$ or $95 \mathrm{~N}_{2} / 5 \% \mathrm{CO}_{2}$ gas for 30 min before slice immersion to ensure $\mathrm{O}_{2}$ saturation or $\mathrm{O}_{2}$ removal was achieved as desired. Baseline measurements were recorded for 10-20 min before oxygen-glucosedeprived exposure. Oxygen-glucose-deprived exposure was implemented for $30 \mathrm{~min}$, and slices were subsequently reperfused with normal ACSF for 40 min. $\quad N, N, N^{\prime}, N^{\prime}$-tetrakis(2-pyridylmethyl)ethylenediamine (TPEN), a membrane-permeable $\mathrm{Zn}^{2+}$ chelator, was administered in the perfusateACSF at a concentration of $100 \mu \mathrm{M}$ during reperfusion as indicated.
Cell viability analysis. To analyze cell death resulting from ischemia and reperfusion and to assess the effect of $\left[\mathrm{Zn}^{2+}\right]_{\mathrm{i}}$ chelation on cell survival, slices were divided into three groups the same way in each of four iterations: control, ischemia, and ischemia with TPEN. After their respective treatments, as detailed below, slices were stained with propidium iodide (PI). The control groups were equilibrated and maintained in room-temperature ACSF bubbled with oxygen for $3 \mathrm{~h}$. The ischemic groups were equilibrated in room-temperature ACSF for 30 min after slicing, subjected to $30 \mathrm{~min}$ oxygen-glucose-deprived insult, and reperfused in normal ACSF for $2 \mathrm{~h}$. The TPEN/ischemia groups were equilibrated in room-temperature ACSF for $30 \mathrm{~min}$, exposed to $100 \mu \mathrm{M}$ TPEN/oxygen-glucose-deprived ACSF for $30 \mathrm{~min}$, and reperfused with $100 \mu \mathrm{M}$ TPEN/normal ACSF for $2 \mathrm{~h}$. The implementation of a $2 \mathrm{~h}$ postinsult time duration was used to allow sufficient time for membrane damage to register and promote the detection of ischemically damaged cells by PI. PI staining was performed by incubating the sections with PI $(5 \mu \mathrm{g} / \mathrm{ml}$ in ACSF) for $30 \mathrm{~min}$ at room temperature after the respective treatments. PI fluorescence (excitation, $545 \mathrm{~nm}$; emission, $645 \mathrm{~nm}$ ) was analyzed and expressed as relative fluorescent intensity differences between experimental groups and control groups. PI fluorescence was recorded using a Zeiss Axiovert LSM 510 inverted microscope (laser scanning microscope). A one-way ANOVA was used to analyze the relative fluorescent intensity differences between the three groups tested, and a two-tailed $t$ test was used as a test for significance $(\alpha=0.01)$.

Colocalization analysis. Colocalization of PI and NG staining was accomplished by performing two-channel laser scans of slices using confocal microscopy. A $488 \mathrm{~nm}$ krypton argon laser line was used for excitation of NG with a $505 \mathrm{~nm}$ emission filter. A $545 \mathrm{~nm}$ helium neon laser line with an excitation filter of $545 \mathrm{~nm}$ was used for excitation of PI with a 645 $\mathrm{nm}$ emission filter. After scanning, Zeiss imaging software produced single-channel results and a composite image compiled by fluorescent overlay. Colocalization experiments were conducted with minimal laser intensity and exposure time to minimize photobleaching.

Data analyses. For time-lapse ischemia experiments, baseline intensity was recorded and expressed as the mean stable fluorescence intensity of a slice region over the 10-20 min period preceding oxygen-glucosedeprived perfusion. Background intensity was determined from tissuefree regions (i.e., next to the slice) in images, and this background was subtracted from baseline recordings. Oxygen-glucose-deprived and reperfusion-induced fluorescence change for each individual slice region was expressed as the change in fluorescence intensity relative to the baseline signal of each region. For time-lapse recordings, the effect of photobleaching was corrected by applying a least-squares curve-fit regression function derived from measurements of extended baseline slice behavior (data not shown) recorded from control experiments in which ischemia was not induced. Changes in cell fluorescence intensity were measured through simple two-group comparisons and analyzed by Student's paired $t$ tests $(\alpha=0.05)$ or single-factor ANOVA.

Materials. The fluorescent dyes Calcium Green-1 AM, NG DCF diacetate, TPEN, and Pluronic F-127 (20\% w/v in DMSO) were obtained from Invitrogen (Carlsbad, CA). All other chemicals were obtained from Sigma or Fluka.

\section{Results}

\section{Intracellular $\mathrm{Zn}^{2+}$ transients during ischemia, as simulated by OGD and reperfusion}

Intracellular $\mathrm{Zn}^{2+}$ elevation during OGD and reperfusion

In this study, we loaded hippocampal slices with the $\mathrm{Zn}^{2+}$ selective fluorescent indicator NG diacetate ester to determine and to characterize increases in intracellular $\mathrm{Zn}^{2+}$. Another reason for choosing NG for this study is that its fluorescence is not appreciable in the presence of physiological levels of $\mathrm{Ca}^{2+}$ and $\mathrm{Mg}^{2+}$ (Canzoniero et al., 1999; Li et al., 2001a,b; Martin et al., 2006). This property in a $\mathrm{Zn}^{2+}$ indicator is critical for this experiment, particularly in differentiating $\mathrm{Zn}^{2+}$ signals from $\mathrm{Ca}^{2+}$ signals. The CA1 region of the hippocampus was chosen as the region of interest because of its increased vulnerability to ischemic damage when compared with other regions and because it 
A.

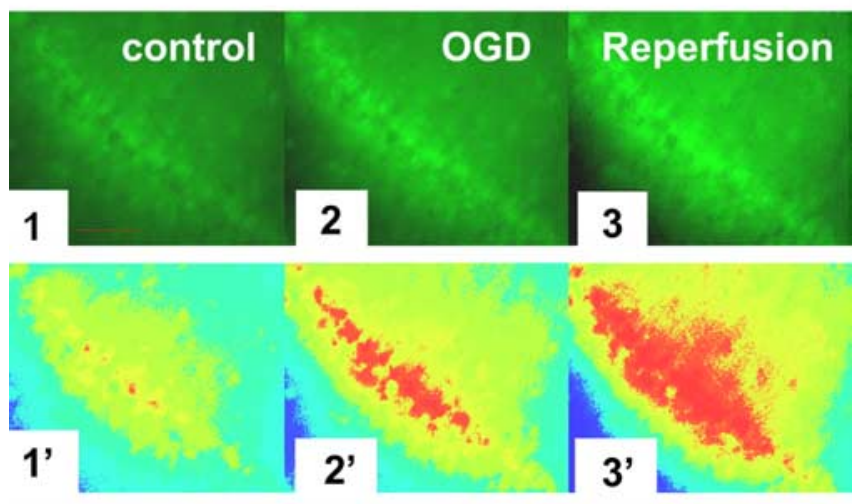

B.

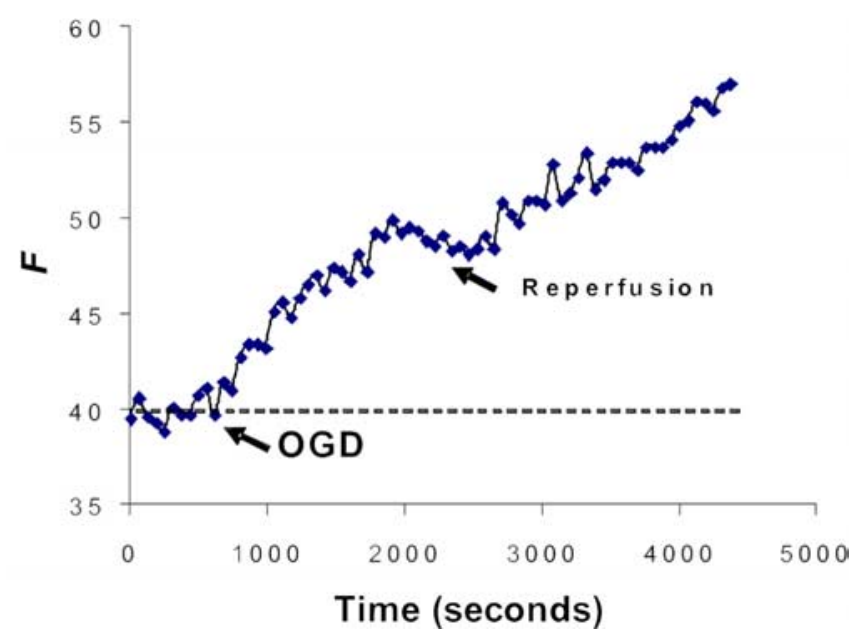

Figure 1. $N G$ detection of $\left[\mathrm{Zn}^{2+}\right]_{\mathrm{i}}$ increase during $O G D$ and reperfusion. $A$, Images of the CA1 region of a hippocampal slice preloaded with NG diacetate ester as described in Materials and Methods. The fluorescence intensities of CA1 pyramidal cells were examined for at least 10 min before (1), during (2), and after (3) perfusion with oxygen-glucose-deprived ACSF bubbled with $95 \% \mathrm{~N}_{2} / 5 \% \mathrm{CO}_{2}$. The oxygen- glucose-deprived insult was administered for $30 \mathrm{~min}$, and the slice was reperfused with normal oxygenated ACSF for 40 min. Images $\mathbf{1}^{\prime}-\mathbf{3}^{\prime}$ are pseudocolor images of images $\mathbf{1 - 3}$. Scale bars, $100 \mu \mathrm{m}$. $\boldsymbol{B}$, A representative graph shows the measured change of $\mathrm{NG}$ fluorescence intensity, indicating increases in intracellular $\mathrm{Zn}^{2+}$ during the course of OGD and reperfusion. Arrows show the start of OGD-simulated ischemia and reperfusion, respectively. The $y$-axis represents the fluorescence emission intensity of the dye/ ion complex in arbitrary units.

has been studied extensively. After recording baseline fluorescence, hippocampal slices were subjected to $30 \mathrm{~min}$ of OGD. A duration of $30 \mathrm{~min}$ OGD was chosen because $\left[\mathrm{Zn}^{2+}\right]_{\mathrm{i}}$ reached a maximum concentration after a prolonged exposure of 30-40 min (Wei et al., 2004). The oxygen-glucose-deprived exposures were followed by reperfusion with normal oxygenated ACSF. The data indicated gradual increases in $\left[\mathrm{Zn}^{2+}\right]_{\mathrm{i}}$ with increasing oxygen-glucose-deprived time. Subsequent reperfusion resulted in an additional increase in intracellular $\mathrm{Zn}^{2+}$ (Fig. 1). The amplitudes of fluorescence intensity were depicted in arbitrary units, and were measured from the baseline to the peak of fluorescent responses. The amplitudes were $6.6 \pm 1.1$ (mean $\pm \mathrm{SE}$ ) in OGD and $16.3 \pm 1.7$ (mean $\pm \mathrm{SE}$ ) in reperfusion; fluorescent values were significantly higher in reperfusion $(p<0.01 ; n=10)$.

Nitric oxide induced the increase in $\left[\mathrm{Zn}^{2+}\right]_{i}$ in neurons Figure 2 shows evidence that nitric oxide $(\mathrm{NO})$ can induce accumulation of $\left[\mathrm{Zn}^{2+}\right]_{\mathrm{i}}$. The application of the NO donor (Fig.
$2 A, C)$, spermine-NONOate, released exogenous NO and resulted in $\mathrm{Zn}^{2+}$-specific fluorescence increase. When $500 \mu \mathrm{M}$ spermine-NONOate was dissolved, NO was liberated in a timedependent manner (5-10 min.), leaving the polyamine, spermine, as a by-product. Control tests were done with spermine (500 $\mu \mathrm{M}, 20 \mathrm{~min}$ ) to ensure that the $\mathrm{Zn}^{2+}$ release by spermineNONOate resulted from the action of NO itself, and not a property of the polyamine remaining after the liberation of NO. There was no change of NG fluorescence in control hippocampal slices incubated in the presence or in the absence of spermine (Fig. $2 B, D)$. Spermine-NONOate produced a significant enhancement in $\left[\mathrm{Zn}^{2+}\right]_{\mathrm{i}}$ detected with NG, suggesting a mechanism for the regulation of $\mathrm{Zn}^{2+}$ homeostasis under OGD and reperfusion. These data support NO as a causal agent in the fluorescence changes, as has been documented previously (Cuajungco and Lees, 1998; Frederickson et al., 2002; Bossy-Wetzel et al., 2004). Furthermore, these results support the previous observation that the NO synthase inhibitor L-NAME inhibited 60 $70 \%$ of the accumulation of $\mathrm{Zn}^{2+}$ in both OGD and reperfusion (Wei et al., 2004).

Elevated $\mathrm{Zn}^{2+}$ contributes to signals previously interpreted as $\mathrm{Ca}^{2+}$ under ischemic conditions

Selectivity of $\mathrm{Ca}^{2+}$ fluorescent indicator Calcium Green-1

Although most $\mathrm{Ca}^{2+}$ indicators have a higher affinity for $\mathrm{Zn}^{2+}$ than for $\mathrm{Ca}^{2+}$ (Grynkiewicz et al., 1985; Tsien and Pozzan, 1989), it has been assumed that the presence of physiologically relevant $\mathrm{Ca}^{2+}$ in the sample will prevent $\mathrm{Zn}^{2+}$ from binding to fluorescent $\mathrm{Ca}^{2+}$ indicators, possibly by surrounding the indicator with a sufficient number of $\mathrm{Ca}^{2+}$ molecules. We investigated metal ion responses by screening Calcium Green-1 for $\mathrm{Zn}^{2+}$ in physiological solutions containing various metal ion concentrations (Martin et al., 2006). We also studied $\mathrm{Zn}^{2+}$ selectivity over $\mathrm{Ca}^{2+}$ by the measurement of $\mathrm{Zn}^{2+}$ responses in the presence of a relatively large $\mathrm{Ca}^{2+}$ concentration. Even when saturating the probe with $\mathrm{Ca}^{2+}$ before the addition of $\mathrm{Zn}^{2+}$, the indicator continued to report zinc concentrations with fidelity. Our recent work (Martin et al., 2006) shows how Calcium Green-1, a widely used fluorescent calcium indicator, was still capable of detecting $\mathrm{Zn}^{2+}$ in the presence of a physiologically relevant $\mathrm{Ca}^{2+}$ concentration (2 mM). In these experiments, the baseline fluorescence was set after the addition of $\mathrm{Ca}^{2+}$ and was readjusted before adding $\mathrm{Zn}^{2+}$ to account for the background fluorescence caused by $\mathrm{Ca}^{2+}$. There was no difference in the concentration-response relationship to $\mathrm{Zn}^{2+}$ sensing obtained with or without $\mathrm{Ca}^{2+}$ being present. These data show these fluorescent $\mathrm{Ca}^{2+}$ probes to be sensitive to $\mathrm{Zn}^{2+}$, in such a way that the presence of physiological $\mathrm{Ca}^{2+}$ minimally disturbs their response to changes in $\left[\mathrm{Zn}^{2+}\right]$.

Calcium Green-1 is a fluorescent indicator designed to bind free $\mathrm{Ca}^{2+}$ ions and fluoresce. This binding is considered to be mediated by the lone pair of electrons from four carboxylate oxygens and two nitrogen atoms of its 1,2-bis(oaminophenoxy)ethane $N, N, N^{\prime}, N^{\prime}$-tetraacetic acid (BAPTA) motif. It is known that such tetracarboxylate $\mathrm{Ca}^{2+}$ indicators also bind to zinc ions, and empirically, if $\mathrm{Ca}^{2+}$ and $\mathrm{Zn}^{2+}$ compete for a binding site on Calcium Green-1, then one would expect not to see a change in fluorescence as $\mathrm{Zn}^{2+}$ is added to a $\mathrm{Ca}^{2+} /$ Calcium Green-1 solution. However, this is not the case; our Calcium Green-1 fluorescence for $\mathrm{Zn}^{2+}$ and $\mathrm{Ca}^{2+}$ detection indicates that the molecule can continue to detect changes in $\mathrm{Zn}^{2+}$ even when $\left[\mathrm{Ca}^{2+}\right]$ is two orders of magnitude larger than the $K_{\mathrm{D}}$. To explore our observations of the interactions of Calcium Green-1 with $\mathrm{Zn}^{2+}$, we used molecular mechanical methods to model the 
A.
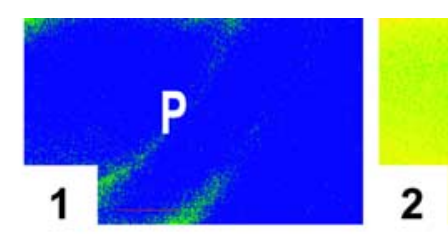

B.

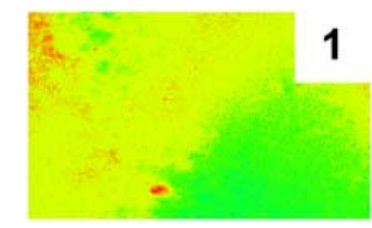

1

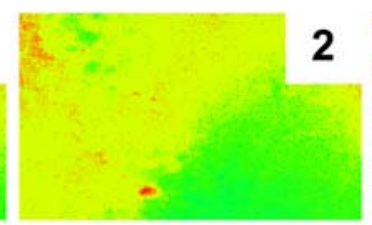

2

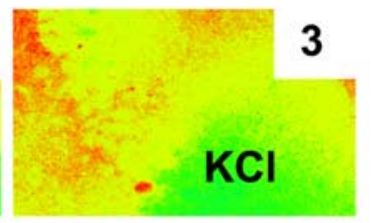

C.

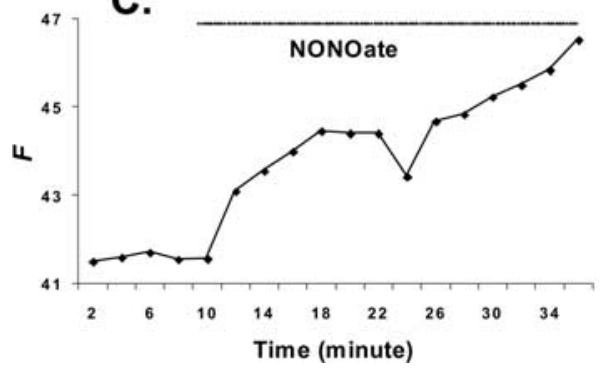

D.

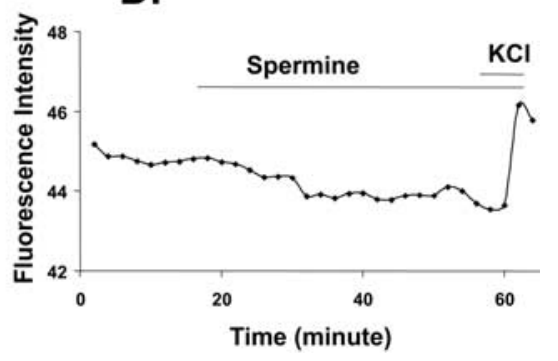

Figure 2. Spermine-NONOate, an NO donor, produces a significant enhancement in $\left[\mathrm{Zn}^{2+}\right]_{\mathrm{i}} . A$, Images indicate that NO released from spermine-NONOate caused an increase in $\left[\mathrm{Zn}^{2+}\right]_{\mathrm{i}}$ detected with $\mathrm{NG}$ in the CA1 region of a hippocampal slice. The left image (1) is the control. The middle (2) and right (3) images were taken 10 and $20 \mathrm{~min}$, respectively, after the start of perfusion with spermine-NONOate. P, Pyramidal cell layer. Scale bars, $100 \mu \mathrm{m}$. B, Images of the control experiment with spermine showing no change in NG fluorescence in the absence of spermine (1) or in the presence of $500 \mu \mathrm{m}$ spermine (2). KCl (60 mM), which increased the fluorescence (3), was applied at the end of the experiment to verify the viability of the hippocampal slice. Scale bars, $100 \mu \mathrm{m}$. C, An individual graph shows that N0 increased in $\left[\mathrm{Zn}^{2+}\right]_{\mathrm{i}}$ detected with NG. D, A graph shows that spermine does not increase NG fluorescence in control hippocampal slices.

binding dynamics of the indicator (data not shown). Our model showed that additional coordination of a $\mathrm{Zn}^{2+}$ ion to the carboxylate oxygen and the amide carbonyl on the central ring of the indicator may occur even when $\mathrm{Ca}^{2+}$ is already bound. Such binding created a $\mathrm{Zn}^{2+}$-carboxylate in the syn configuration, the dominant mode of bonding interaction seen in carboxylate metal-ligand interaction (Holm et al., 1996). The second bond interaction through the amide carbonyl oxygen atom is in agreement with sites of amide-metal ion coordination in many proteins (Holm et al., 1996). In this model, the bond distance is $2.51 \AA$, which is greater than the average $\mathrm{Zn}$-donor atom distance, although $2.5 \AA$ is considered the average bond distance for $\mathrm{Zn}-$ $\mathrm{O}_{\text {Glutamate }}$ interaction (Hammes and Carrano, 1999). This bond distance of $2.51 \AA$ is also seen in the transition state of farnesyltransferase, a zinc metalloenzyme (Sousa et al., 2005). All molecular calculations were performed using ArgusLab 4.0 (Planaria Software, Seattle, WA).

Fluorescent $\mathrm{Ca}^{2+}$ probe detecting cellular $\mathrm{Zn}^{2+}$

Next, we studied whether a commonly used fluorescent $\mathrm{Ca}^{2+}$ indicator such as Calcium Green-1 can detect $\mathrm{Zn}^{2+}$ in situ. To test this speculation, cultured neurons were preloaded with Calcium Green-1 AM and placed in a recording chamber on the microscope stage with continuous perfusion of ACSF (without added $\mathrm{Ca}^{2+}$ ). To investigate whether $\mathrm{Zn}^{2+}$ can be detected in situ

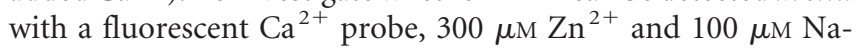
pyrithione, $\mathrm{a}^{2+}$ ionophore that facilitates ion influx into cells, were added to the perfusate. In the presence of $\mathrm{Zn}^{2+}$ alone, minimal change of intracellular fluorescence of Calcium Green-1 was observed (Fig. 3B). Pyrithione, when administered alone without $\mathrm{Zn}^{2+}$, also resulted in minimal change of fluorescence. Increases

in $\left[\mathrm{Zn}^{2+}\right]_{\mathrm{i}}$ were detected when both $\mathrm{Zn}^{2+}$ and pyrithione were perfused, and the fluorescent signal was reversible with the addition of TPEN, a membrane-permeable $\mathrm{Zn}^{2+}$ chelator. TPEN (Fig. $3 A$ ) has a very high affinity for $\mathrm{Zn}^{2+}\left(K_{\mathrm{D}}=2.6 \times 10^{-16}\right.$ M) but a relatively low affinity for $\mathrm{Ca}^{2+}$ $\left(K_{\mathrm{D}}=4.0 \times 10^{-5} \mathrm{M}\right)$ and $\mathrm{Mg}^{2+}\left(K_{\mathrm{D}}=\right.$ $\left.2.0 \times 10^{-2} \mathrm{M}\right)$. This result indicated that the influx of $\mathrm{Zn}^{2+}$ and a rise in $\left[\mathrm{Zn}^{2+}\right]_{\mathrm{i}}$ changed the fluorescent intensity of Calcium Green-1 and demonstrated that these fluorescent $\mathrm{Ca}^{2+}$ indicators can effectively measure the dynamic change of cytosolic $\mathrm{Zn}^{2+}$ in situ.

Calcium Green-1 AM detection of $\left[\mathrm{Zn}^{2+}\right]_{i}$ increase during ischemia and reperfusion Our results raise the important issue of whether $\mathrm{Zn}^{2+}$ transients can contribute to the $\mathrm{Ca}^{2+}$ transients conventionally detected with fluorescent probes. This question has become logical recently because growing evidence has demonstrated an increase in $\left[\mathrm{Zn}^{2+}\right]_{\mathrm{i}}$ in concomitance with various neural activities (Frederickson et al., 2005) (Fig. 1). When the hippocampal slice was loaded with cell-permeable Calcium Green-1, as expected, a steady increase in fluorescence intensity was detected during OGD and reperfusion (Fig. 4). Because Calcium Green-1 is also sensitive to $\mathrm{Zn}^{2+}$, as indicated above, we examined the extent to which $\mathrm{Zn}^{2+}$ signals contributed to the $\mathrm{Ca}^{2+}$ signal. The zinc chelator TPEN was then added at the peak of the fluorescence intensity to reveal the $\mathrm{Zn}^{2+}$ signal component. In these experiments, the addition of TPEN after reperfusion with normal ACSF reduced the amplitude of Calcium Green-1 fluorescence. The peak fluorescence intensity in arbitrary units was $10.3 \pm 2.03($ mean $\pm S E)$ in OGD, $16.78 \pm 2.78($ mean $\pm S E)$ in reperfusion, and $4.44 \pm 2.52$ (mean \pm SE) in TPEN $(p<0.01$ compared with baseline value; $n=9$ ). TPEN did not always diminish the fluorescence to the baseline value. The remaining fluorescence in the presence of TPEN may be the $\mathrm{Ca}^{2+}$ component. These data show that $\mathrm{Zn}^{2+}$ ions contribute significantly to rising fluorescence intensity measured with $\mathrm{Ca}^{2+}$ indicators in OGD and reperfusion.

\section{Elevated $\mathrm{Zn}^{2+}$ is a major factor in neuronal cell death during ischemic stroke}

TPEN prevents pyramidal neurons from sustaining

ischemic damage

We examined the extent of CA1 pyramidal neuronal injury resultant after oxygen-glucose-deprived exposure. These experiments used the fluorescent cell-death marker PI to assess injury. PI is a cell membrane-impermeant dye that becomes brightly fluorescent after binding to DNA in dead cells. It enters injured neurons in which the plasma membrane is disrupted and is shown to preferentially accumulate in the nucleus of dying neurons. Hippocampal slices were grouped into control (incubation with normal ACSF), OGD/reperfusion (30 min OGD), and TPEN-treated groups. After OGD, the slices were incubated for $2 \mathrm{~h}$ in oxygenated media. In the TPEN treatment groups, TPEN 


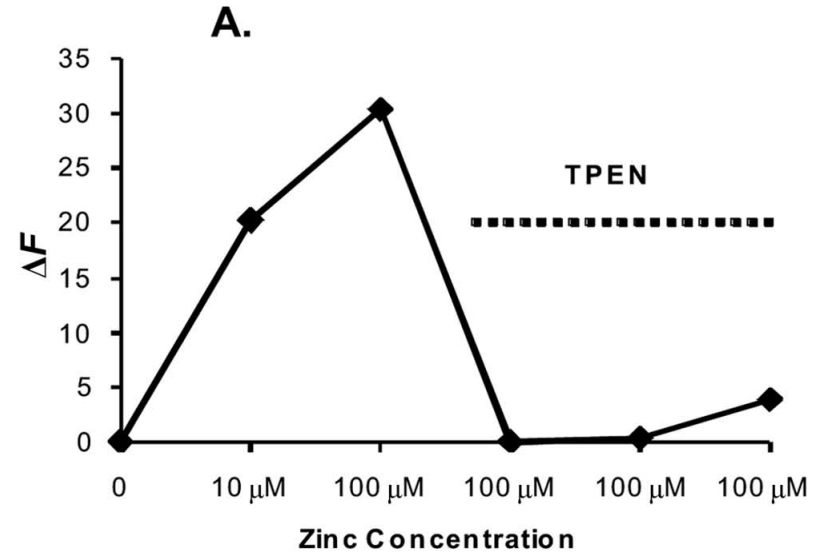

B.

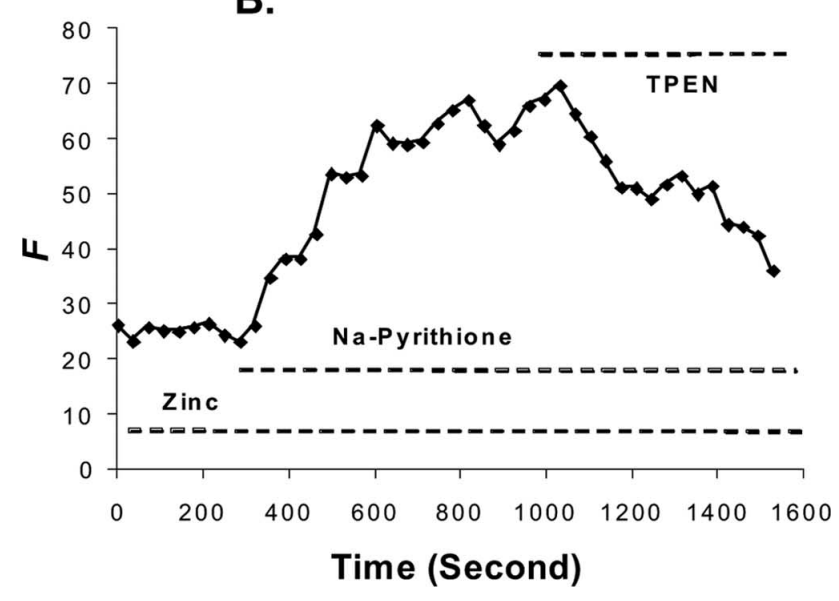

Figure 3. $\mathrm{Zn}^{2+}$ chelator TPEN reduces Calcium Green-1 fluorescence. $A$, Calcium Green-1 detecting zinc and ameliorated by TPEN. A graph of fluorescence intensity from Calcium Green-1 with the addition of $\mathrm{Zn}^{2+}$ at 10 and $100 \mu \mathrm{m}$ with signal abatement when $50 \mu \mathrm{M}$ TPEN was applied is shown. The experiments were conducted in ACSF adjusted to $\mathrm{pH}$ 7.4. The concentration of Calcium Green- 1 is $1 \mu \mathrm{m}$. SE at $1 \mu \mathrm{m} \mathrm{Zn^{2+ }}$ is \pm 2 intensity units and at $100 \mu \mathrm{m}$ is \pm 4 intensity units; $n=5$. The $y$-axis represents the fluorescence emission intensity $(F)$ of the dye/ion complex minus the fluorescence of the baseline $\left(F_{0}\right) . \Delta F=F-F_{0}$. B, Detecting cellular $\mathrm{Zn}^{2+}$ with membrane-permeable Calcium Green-1 AM $(10 \mu \mathrm{M})$. A 5 min exposure to $300 \mu \mathrm{M}$ $\mathrm{Zn}^{2+}$ produced no change in Calcium Green-1 fluorescence. The subsequent addition of 100 $\mu \mathrm{M} \mathrm{Na}{ }^{+}$pyrithione, a $\mathrm{Zn}^{2+}$ ionophore, with $\mathrm{Zn}^{2+}$ resulted in a progressive increase in fluorescence. № $\mathrm{Ca}^{2+}$ was added in the perfusate. Finally, Calcium Green-1 fluorescence was reduced by the addition of $100 \mu \mathrm{M}$ TPEN. The $y$-axis represents the fluorescence emission intensity of the dye/ion complex in arbitrary units.

was present in the perfusate of OGD and reperfusion and was then withdrawn from ACSF 30 min after reperfusion. The slices in the control groups were incubated in normal ACSF for the same time duration as both of the other groups. PI was added during the final $30 \mathrm{~min}$ of the incubation, followed by fixation and subsequent visualization of PI fluorescence using confocal microscopy. Images were obtained deep (75-100 $\mu \mathrm{m})$ within the slice, where injury resulting from the trauma of slicing is minimized. A set of examinations was stopped if $>5 \%$ of cells stained in the control slice. Figure 5 shows that little PI fluorescence was seen in pyramidal cell layers of the control group, but a strong signal was present in the OGD/reperfusion group. Subsequent experiments examined the effect of TPEN on the extent of pyramidal neuronal injury resulting from oxygen-glucose-deprived exposure. PI labeling was decreased significantly $(p<0.05 ; n=6$ slices per group) by TPEN. Post hoc analysis using the Bonferroni method showed the ischemia group to be different from the

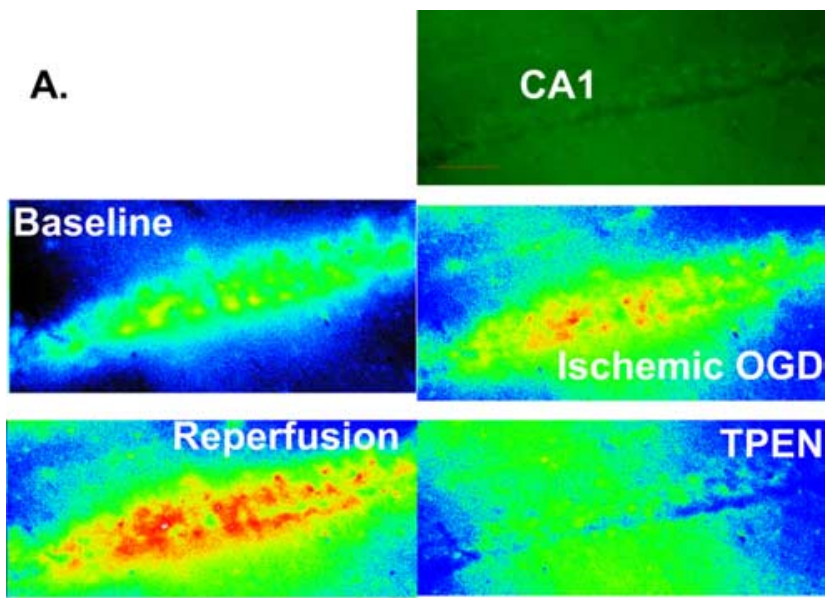

B.

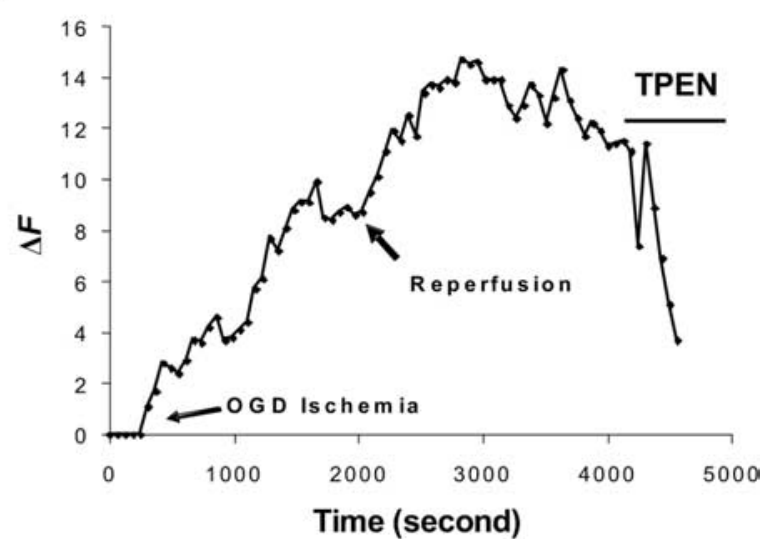

C.

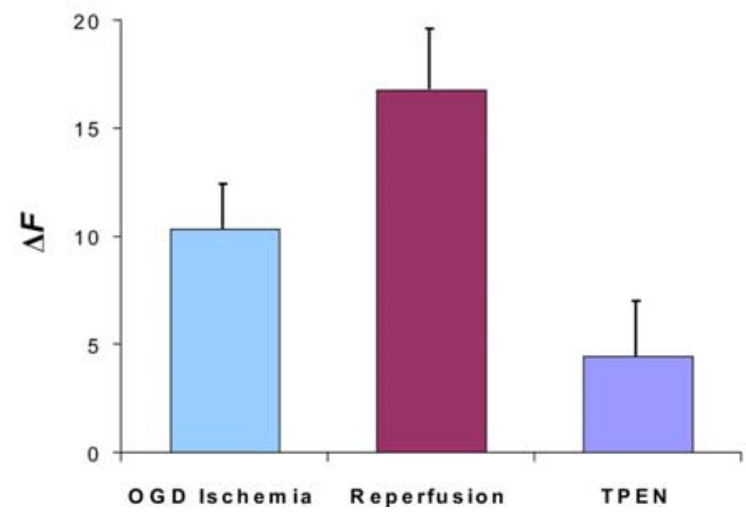

Figure 4. Calcium Green-1 detects $\left[\mathrm{Zn}^{2+}\right]_{\mathrm{i}}$ elevation during ischemia and reperfusion. $\boldsymbol{A}$, Sequential pseudocolor images of the CA1 region of a hippocampal slice loaded with cellpermeable Calcium Green-1 taken at baseline, $0 G D$, reperfusion, and with the addition of 100 $\mu \mathrm{M}$ TPEN. Images were taken through a $10 \times$ Plan-Neofluar objective. The first image is an original image of the baseline. $\boldsymbol{B}$, Graph showing the typical increases in Calcium Green-1 fluorescence during $O G D$ and reperfusion in a rat hippocampal slice. Arrows show the start of OGD-simulated ischemia and reperfusion, followed by the addition of $100 \mu \mathrm{M}$ TPEN. TPEN reduced fluorescence intensity. $C$, Histogram showing the relative fluorescent changes during ischemia, reperfusion, and the addition of TPEN (means $\pm \mathrm{SE} ; n=9$ ). The $y$-axes in $\boldsymbol{B}$ and $\boldsymbol{C}$ represent the fluorescence emission intensity $(F)$ of the dye/ion complex minus the fluorescence of the baseline $\left(F_{0}\right) . \Delta F=F-F_{0}$.

TPEN and control groups (95\% confidence level). Expressed as percentage difference of fluorescence intensity from control (control intensity considered to be 1.0 , or 100\%), the OGD/ reperfusion group was measured at 2.07 times higher average fluorescence or $207 \%$ of control, and the TPEN treatment during 
A. Control
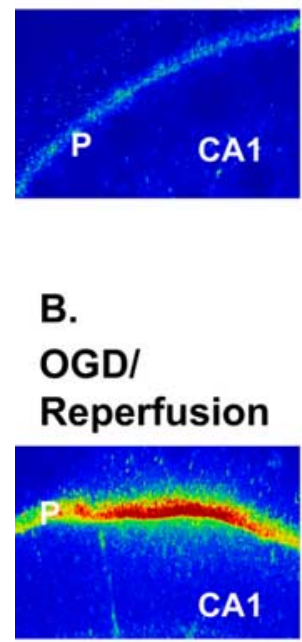

C. TPEN

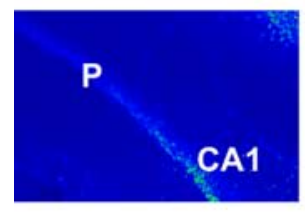

D.

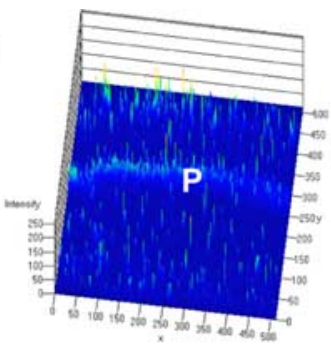

E.

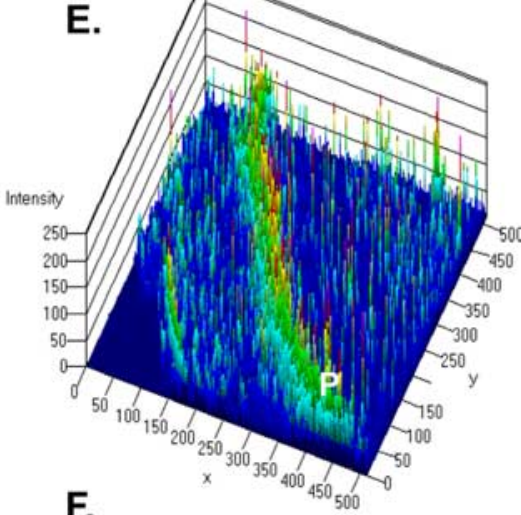

F.

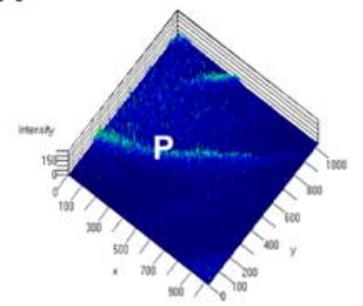

Figure 5. PI-stained photomicrographs by confocal microscopy show PI staining of degenerating neurons after $0 G D$ and reperfusion in the CA1 region of hippocampus. $\boldsymbol{A}-\boldsymbol{C}$, Images of the $C A 1$ region acquired with confocal microscopy. Images were taken through a $10 \times$ PlanNeofluar objective. P, Pyramidal cell layer. $\boldsymbol{D}-\boldsymbol{F}$, Three-dimensional analyses with LSM 5 Image software (Carl Zeiss AIM; Zeiss). The fluorescence intensity is analyzed against distance of the slice in two dimensions. Little PI fluorescence was seen in pyramidal cell layers of the normal condition $(\boldsymbol{A}, \boldsymbol{D})$, but a strong signal was present in the condition of $0 \mathrm{GD} /$ reperfusion $(\boldsymbol{B}, \boldsymbol{E})$. Strong PI labeling was prevented by the addition of $100 \mu \mathrm{M}$ TPEN in ACSF $(\boldsymbol{C}, \boldsymbol{F})$.

OGD/reperfusion was measured at 1.22 times average higher fluorescence or $122 \%$ of control. These observations indicate that the $\mathrm{Zn}^{2+}$ buildup in pyramidal neurons during OGD and reperfusion is a causal factor in the resultant ischemic injury. Furthermore, the removal of $\left[\mathrm{Zn}^{2+}\right]_{\mathrm{i}}$ by chelation prevents pyramidal neurons from sustaining extensive ischemic damage.

Colocalization of the increase in $\left[\mathrm{Zn}^{2+}\right]_{i}$ and neuronal cell death In a separate experiment, cell viability was comparatively determined with dual staining of PI and cell-impermeant NG in hippocampal slices that were subjected to OGD/reperfusion. When viewed using a fluorescence microscope ( $645 \mathrm{~nm}$ filter), cells that lost membrane integrity showed contrasting red PI staining throughout the nuclei (Fig. 6A) in the same tissue sections that also stained initially with cell-impermeant NG (Fig. $6 B$ ). Therefore, the dual fluorescent staining, or colocalization, of PI and NG staining showed agreement between endogenous increases in $\left[\mathrm{Zn}^{2+}\right]_{\mathrm{i}}$ and indications of neuronal damage (Fig. 6C) with Pearson's correlation coefficient $r=.743(n=28)$ (Stork and Li, 2006). These data suggested that cells labeled with NG were damaged and becoming necrotic or undergoing apoptotic cell death. Signal overlap was ruled out as a factor responsible for the higher intensity of NG nuclear fluorescence by examining slices stained only with PI and performing scans using the same NG examination parameters as during colocalization experiments; results showed only minimal background intensity. Conversely, using excitation and emission wavelengths for NG, we did not observe PI staining (data not shown) in slices stained only with PI.

\section{Discussion}

First, our results indicate that there is a rapid $\mathrm{Zn}^{2+}$ accumulation in acute rat hippocampus slices during OGD and reperfusion, which demonstrates that the divalent cation $\mathrm{Zn}^{2+}$ accumulates in concomitance with cerebral ischemic insults. The second, and major, finding is that intracellular $\mathrm{Zn}^{2+}$ elevation can contribute to signals previously interpreted as $\mathrm{Ca}^{2+}$ overload conventionally identified by using " $\mathrm{Ca}^{2+}$-specific" fluorescent indicators. Finally, the progressive rise in $\left[\mathrm{Zn}^{2+}\right]_{\mathrm{i}}$ levels during ischemic insult corresponds with neuronal death in the hippocampal slice, and $\mathrm{Zn}^{2+}$ chelation prevents hippocampal neurons from developing injury during OGD/reperfusion.

\section{Fluorescent $\mathrm{Ca}^{2+}$ probes}

Most of these fluorescent indicators are derivatives of the $\mathrm{Ca}^{2+}$ chelators BAPTA, EGTA, and aminophenol triacetic acid (APTRA) (Tsien and Pozzan, 1989; Haugland, 2001), which also bind $\mathrm{Zn}^{2+}$ with significantly higher affinity. The $K_{\mathrm{D}}$ values of BAPTA are as follows (Grynkiewicz et al., 1985; Haugland, 2001): $\mathrm{Ca}^{2+}, 160 \mathrm{~nm} ; \mathrm{Zn}^{2+}, 8 . n \mathrm{n}$. The $K_{\mathrm{D}}$ values of EGTA are as follows: $\mathrm{Ca}^{2+}, 0.38 \mathrm{nM} ; \mathrm{Zn}^{2+}, 7.8$ pM. The $K_{\mathrm{D}}$ values of APTRA are as follows: $\mathrm{Ca}^{2+}, 12 \mu \mathrm{M} ; \mathrm{Zn}^{2+}, 19 \mathrm{nM}$. Therefore, a critically relevant fact, often ignored in the past, is that almost all $\mathrm{Ca}^{2+}$ fluorescent indicators are also sensitive to $\mathrm{Zn}^{2+}$ with an even higher affinity. For example, $\mathrm{Zn}^{2+}$ binds to most BAPTA-based $\mathrm{Ca}^{2+}$ indicators with substantially higher affinity than $\mathrm{Ca}^{2+}$. Calcium Green-1, a widely used $\mathrm{Ca}^{2+}$ indicator, uses the BAPTA chelator motif, which is shown to bind $\mathrm{Zn}^{2+}$ with a $K_{\mathrm{D}}$ that is nearly two orders of magnitude lower (higher affinity) than that of $\mathrm{Ca}^{2+}$ (see above). As another example, the ubiquitous $\mathrm{Ca}^{2+}$ indicator fura-2 exhibits a $K_{\mathrm{D}}$ for $\mathrm{Zn}^{2+}$ (in the absence of $\mathrm{Ca}^{2+}$ ) of $3 \mathrm{nM}$ (Grynkiewicz et al., 1985; Haugland, 2001).

We have tested the responses of BAPTA-based $\mathrm{Ca}^{2+}$ indicators, including Calcium Green-1, fluo-3, and fura-2 to a series of concentrations of $\mathrm{Ca}^{2+}$ or $\mathrm{Zn}^{2+}$ in a physiological saline (ACSF). All three probes showed an affinity for both $\mathrm{Ca}^{2+}$ and $\mathrm{Zn}^{2+}$, and the response curves representing detection parameters for each divalent ion were very similar (Martin et al., 2006). Fura-2, because of its sensitivity to $\mathrm{Zn}^{2+}$, has even been used to detect intracellular $\mathrm{Zn}^{2+}$ influx via voltage-gated $\mathrm{Ca}^{2+}$ channels (Atar et al., 1995; Aizenman et al., 2000). Although it has been recognized that most $\mathrm{Ca}^{2+}$ indicators have a higher affinity toward $\mathrm{Zn}^{2+}$ rather than $\mathrm{Ca}^{2+}$, it has been assumed that the presence of physiologically relevant $\mathrm{Ca}^{2+}$ in the sample will prevent $\mathrm{Zn}^{2+}$ from binding to fluorescent $\mathrm{Ca}^{2+}$ indicators, possibly by surrounding the indicator with a sufficient number of molecules of $\mathrm{Ca}^{2+}$. As our previous experiments showed, not only are these fluorescent $\mathrm{Ca}^{2+}$ probes sensitive to $\mathrm{Zn}^{2+}$, but the presence of physiologically relevant $\mathrm{Ca}^{2+}$ minimally perturbs their response to $\mathrm{Zn}^{2+}$ (Martin et al., 2006). The evidence clearly supports the use of such probes as effective and efficient $\mathrm{Zn}^{2+}$ indicators. Results such as these reinforce the necessity for a reanalysis of the evidence in which the ionic identities responsible for $\mathrm{Ca}^{2+}$ signals under conditions in which causality has been derived from the detection of $\mathrm{Ca}^{2+}$ by fluorescent indicators.

The binding affinities of $\mathrm{Ca}^{2+}$ and $\mathrm{Zn}^{2+}$ for Calcium Green-1 
may be a critical factor in interpreting the data presented in this study. Evidence on the binding activity of 5-F-BAPTA (a chelator very closely related to the BAPTA group of Calcium Green-1) presented by Csermely et al. (1989) describes a large difference in the binding lifetimes of $\mathrm{Zn}^{2+}$ and $\mathrm{Ca}^{2+}$. They found that $\mathrm{Ca}^{2+}$ binding occurs with a lifetime of $\sim 5 \mathrm{~ms}$, whereas it was found that $\mathrm{Zn}^{2+}$-binding lifetimes lasted approximately five to six times longer, 232 ms (Csermely et al., 1989). Considering that the energy transitions
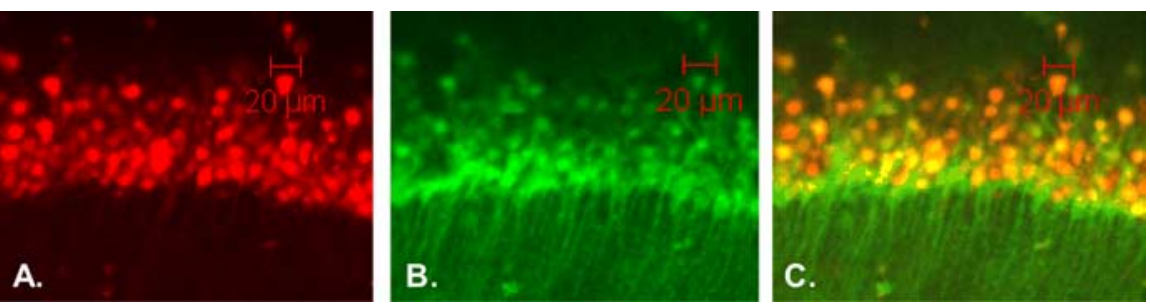

Figure 6. Microscopic fluorescence images of rat hippocampal sections stained with PI and NG. Images of pyramidal cells of a hippocampal CA1 section after $0 G D$ and reperfusion viewed at $40 \times$ are shown. $A$, PI-stained nuclei red with emission at $630 \mathrm{~nm}$. $B$, NG-stained cell bodies green with emission at $505 \mathrm{~nm}$. C, Composite overlay fluorescence images showing colocalization of PI nuclei within cell bodies labeled with NG. Scale bars, $20 \mu \mathrm{m}$. that produce fluorescence occur when the fluorophore is in the bound state, and that photons are produced during a given binding according to duration of binding, the much longer lifetime of a $\mathrm{Zn}^{2+}$-Calcium Green-1 complex would be expected to result in an increased photon emission for a given binding event and would necessarily be interpreted as an increased intensity of emission. Second, our molecular modeling indicates the possibility of an alternate $\mathrm{Zn}^{2+}$-binding mechanism occurring when Calcium Green-1 is already bound to $\mathrm{Ca}^{2+}$ (see Results).

\section{$\mathrm{Zn}^{2+}$ overload versus $\mathrm{Ca}^{2+}$ overload}

Since the theory of calcium mediated excitotoxicity was introduced, large volumes of fluorescent-based evidence has supported this notion of $\left[\mathrm{Ca}^{2+}\right]_{\mathrm{i}}$ elevation during and after ischemic insult. However, therapeutic strategies based on calcium antagonism have met with little success (National Institute of Neurological Disorders and Stroke, 2002). Although transition metal cations like $\mathrm{Zn}^{2+}$ can dominate $\mathrm{Ca}^{2+}$ measurements made with fluorescent indicators and although the $\mathrm{Zn}^{2+}$ sensitivity of fluorescent $\mathrm{Ca}^{2+}$ probes such as fura-2 and Calcium Green-1 has been reported in detail previously (Grynkiewicz et al., 1985; Tsien and Pozzan, 1989), the information concerning $\mathrm{Zn}^{2+}$ sensitivity has essentially been ignored. This has led to the status quo, in which $\mathrm{Zn}^{2+}$ has received comparatively far less study in physiological systems. It has been believed that intracellular concentrations of $\mathrm{Zn}^{2+}$, a trace element in the biological system, are very low (Haugland, 2001).

The present study shows that the calcium indicator Calcium Green-1 detects $\left[\mathrm{Zn}^{2+}\right]_{\mathrm{i}}$ elevation during in vitro ischemia and that chelation of $\left[\mathrm{Zn}^{2+}\right]_{\mathrm{i}}$ during ischemia and reperfusion results in reduced cellular death. Because both $\mathrm{Zn}^{2+}$ and $\mathrm{Ca}^{2+}$ appear to be "overloaded" in ischemia and reperfusion, we ask why there are two such similar signals and what the relationship is between them in ischemia and reperfusion. When hippocampal slices were loaded with cell-permeable Calcium Green-1, as expected, a steady increase in fluorescence intensity was detected during OGD and reperfusion. Application of the selective $\mathrm{Zn}^{2+}$ chelator TPEN diminishes the Calcium Green-1 fluorescence during OGD and reperfusion. These data strongly suggest that $\mathrm{Zn}^{2+}$ contributes predominantly to rising fluorescence intensity measured with $\mathrm{Ca}^{2+}$ indicators in OGD and reperfusion. Furthermore, the data from $\mathrm{Zn}^{2+}$ chelation revealed that $\mathrm{Ca}^{2+}$ signals detected with fluorescent $\mathrm{Ca}^{2+}$ indicators are less significant than previously thought. If results previously attributed to $\mathrm{Ca}^{2+}$ could, in part, be attributed to $\mathrm{Zn}^{2+}$, then the "calcium overload" that has been described in the past, using $\mathrm{Ca}^{2+}$-sensitive indicators, needs to be re-examined to determine whether $\mathrm{Ca}^{2+}$ signals are, in fact, a cause of neuronal damage. Such evidence shows the urgent need for the development of truly selective fluorescent $\mathrm{Ca}^{2+}$ indicators, which we consider integral to furthering the understanding of the role that $\mathrm{Ca}^{2+}$ plays in cellular signaling and pathology.

\section{Zinc homeostasis}

It is well known that $85-90 \%$ of $\mathrm{Zn}^{2+}$ in the body is tightly bound to proteins and is composed mostly of metalloenzyme- and metalloprotein-bound zinc (Choi and Koh, 1998). Metallothioneins can serve as intracellular reservoirs for release of $\mathrm{Zn}^{2+}$ during signaling or during deficiency states. Recently, evidence from our group and others suggested that the reactive-free radical species NO may be involved in the regulation of $\mathrm{Zn}^{2+}$ homeostasis (Cuajungco and Lees, 1998; Snider et al., 2000; Frederickson et al., 2002; St Croix et al., 2002; Bossy-Wetzel et al., 2004; Wei et al., 2004; Zhang et al., 2004). In particular, results in which the NO synthase inhibitor L-NAME reduced $60-70 \%$ of the accumulation of $\mathrm{Zn}^{2+}$ in both OGD and reperfusion (Wei et al., 2004) show significant support for this theory. Additionally, the present study shows that NO directly liberates $\mathrm{Zn}^{2+}$ from its intracellular stores (Fig. 2). The mechanism of NO-mediated $\mathrm{Zn}^{2+}$ release is not entirely understood, but evidence points toward a release from metallothionein and zinc-finger proteins by $S$-nitrosylation of cysteine clusters that bind $\mathrm{Zn}^{2+}$ (Aravindakumar et al., 1999; Maret et al., 1999; Hong and Maret, 2003). In addition to metallothioneins, $\mathrm{Zn}^{2+}$ can be also released from a specific subset of glutamatergic nerve terminals throughout the mammalian cortex of the brain. The released $\mathrm{Zn}^{2+}$ has been shown to then translocate into postsynaptic neurons through $\mathrm{Zn}^{2+}$-permeable channels (Li et al., 2001b, 2003), thereby creating a $\left[\mathrm{Zn}^{2+}\right]_{\mathrm{i}}$ transient. Free intracellular $\mathrm{Zn}^{2+}$ can produce mitochondrial membrane permeability transitions, inhibit respiratory complex I, and cause cytochrome $c$ release (considered a critical step leading toward apoptosis) (Noh et al., 1999; Truong-Tran et al., 2001; Dineley et al., 2003; Bossy-Wetzel et al., 2004). Because it is well known that $\mathrm{NO}$ is generated during ischemia and reperfusion (Beckman, 1991; Moncada and Higgs, 1993; Dawson and Dawson, 2000), these results suggest that NO may be involved in the release of $\mathrm{Zn}^{2+}$ during ischemia and reperfusion.

\section{Conclusion}

It is known that changes in ionic concentration have a fundamental effect on numerous physiological processes related to brain function. Given the results presented in this study, we are convinced that only when truly selective $\mathrm{Ca}^{2+}$ probes are developed can investigators unmitigatingly define the role of $\mathrm{Ca}^{2+}$ signaling in biological processes. On the other hand, the indications that both $\mathrm{Zn}^{2+}$ and $\mathrm{Ca}^{2+}$ appear to be overloaded in ischemic conditions should compel more studies to address the distinctions between $\mathrm{Zn}^{2+}$ and $\mathrm{Ca}^{2+}$. Are there redundant roles and/or separable roles for $\mathrm{Ca}^{2+}$ and $\mathrm{Zn}^{2+}$, and what are these specific 
functions? We hope that additional investigations with the current results in mind can lead to the realignment of current thinking and the production of a workable ischemic therapy.

\section{References}

Aizenman E, Stout AK, Hartnett KA, Dineley KE, McLaughlin B, Reynolds IJ (2000) Induction of neuronal apoptosis by thiol oxidation: putative role of intracellular zinc release. J Neurochem 75:1878-1888.

Aravindakumar CT, Ceulemans J, De Ley M (1999) Nitric oxide induces Zn2+ release from metallothionein by destroying zinc-sulphur clusters without concomitant formation of S-nitrosothiol. Biochem J 344:253-258.

Atar D, Backx PH, Appel MM, Gao WD, Marban E (1995) Excitationtranscription coupling mediated by zinc influx through voltagedependent calcium channels. J Biol Chem 270:2473-2477.

Beckman JS (1991) The double-edged role of nitric oxide in brain function and superoxide-mediated injury. J Dev Physiol 15:53-59.

Benveniste H, Jorgensen MB, Diemer NH, Hansen AJ (1988) Calcium accumulation by glutamate receptor activation is involved in hippocampal cell damage after ischemia. Acta Neurol Scand 78:529-536.

Berridge MJ (1998) Neuronal calcium signaling. Neuron 21:13-26.

Bossy-Wetzel E, Talantova MV, Lee WD, Scholzke MN, Harrop A, Mathews E, Gotz T, Han J, Ellisman MH, Perkins GA, Lipton SA (2004) Crosstalk between nitric oxide and zinc pathways to neuronal cell death involving mitochondrial dysfunction and p38-activated $\mathrm{K}+$ channels. Neuron 41:351-365.

Canzoniero LM, Turetsky DM, Choi DW (1999) Measurement of intracellular free zinc concentrations accompanying zinc-induced neuronal death. J Neurosci 19:RC31(1-6).

Choi DW, Koh JY (1998) Zinc and brain injury. Annu Rev Neurosci 21:347-375.

Clapham DE (1995) Calcium signaling. Cell 80:259-268.

Csermely P, Sandor P, Radics L, Somogyi J (1989) Zinc forms complexes with higher kinetical stability than calcium, 5-F-BAPTA as a good example. Biochem Biophys Res Commun 165: 2:838-844.

Cuajungco MP, Lees GJ (1998) Nitric oxide generators produce accumulation of chelatable zinc in hippocampal neuronal perikarya. Brain Res 799:118-129.

Dawson VL, Dawson TM (2000) Neuronal ischaemic preconditioning. Trends Pharmacol Sci 21:423-424.

Dineley KE, Votyakova TV, Reynolds IJ (2003) Zinc inhibition of cellular energy production: implications for mitochondria and neurodegeneration. J Neurochem 85:563-570.

Frederickson CJ, Cuajungco MP, LaBuda CJ, Suh SW (2002) Nitric oxide causes apparent release of zinc from presynaptic boutons. Neuroscience 115:471-474.

Frederickson CJ, Koh JY, Bush AI (2005) The neurobiology of zinc in health and disease. Nat Rev Neurosci 6:449-462.

Grynkiewicz G, Poenie M, Tsien RY (1985) A new generation of Ca2+ indicators with greatly improved fluorescence properties. J Biol Chem 260:3440-3450.

Hammes BS, Carrano CJ (1999) Synthesis and characterization of pseudotetrahedral $\mathrm{N}(2) \mathrm{O}$ and $\mathrm{N}(2) \mathrm{S}$ zinc(II) complexes of two heteroscorpionate ligands: models for the binding sites of several zinc metalloproteins. Inorg Chem 38:4593-4600.

Haugland HP (2001) Handbook of fluorescent probes and research chemicals, Ed 6. Eugene, OR: Molecular Probes.

Holm RH, Kennepohl P, Solomon EI (1996) Structural and functional aspects of metal sites in biology. Chem Rev 96:2239-2314.

Hong SH, Maret W (2003) A fluorescence resonance energy transfer sensor for the beta-domain of metallothionein. Proc Natl Acad Sci USA 100:2255-2260

Koh JY, Suh SW, Gwag BJ, He YY, Hsu CY, Choi DW (1996) The role of zinc in selective neuronal death after transient global cerebral ischemia. Science 272:1013-1016.

Lee JM, Zipfel GJ, Park KH, He YY, Hsu CY, Choi DW (2002) Zinc translocation accelerates infarction after mild transient focal ischemia. Neuroscience 115:871-878.

Li Y, Hough CJ, Frederickson CJ, Sarvey JM (2001a) Induction of mossy fiber $\rightarrow$ Ca3 long-term potentiation requires translocation of synaptically released $\mathrm{Zn}^{2+}$. J Neurosci 21:8015-8025.

Li Y, Hough CJ, Suh SW, Sarvey JM, Frederickson CJ (2001b) Rapid translocation of $\mathrm{Zn}(2+)$ from presynaptic terminals into postsynaptic hip- pocampal neurons after physiological stimulation. J Neurophysiol 86:2597-2604.

Li YV, Hough CJ, Sarvey JM (2003) Do we need zinc to think? Sci STKE 2003:pe19.

Lobner D, Canzoniero LM, Manzerra P, Gottron F, Ying H, Knudson M, Tian M, Dugan LL, Kerchner GA, Sheline CT, Korsmeyer SJ, Choi DW (2000) Zinc-induced neuronal death in cortical neurons. Cell Mol Biol (Noisyle-grand) 46:797-806.

Manev H, Kharlamov E, Uz T, Mason RP, Cagnoli CM (1997) Characterization of zinc-induced neuronal death in primary cultures of rat cerebellar granule cells. Exp Neurol 146:171-178.

Maret W, Jacob C, Vallee BL, Fischer EH (1999) Inhibitory sites in enzymes: zinc removal and reactivation by thionein. Proc Natl Acad Sci USA 96:1936-1940.

Martin JL, Stork CJ, Li YV (2006) Determining zinc with commonly used calcium and zinc fluorescent indicators, a question on calcium signals. Cell Calcium 40:393-402.

Moncada S, Higgs A (1993) The L-arginine-nitric oxide pathway. N Engl J Med 329:2002-2012.

National Institute of Neurological Disorders and Stroke (2002) Report of the Stroke Progress Review Group. Bethesda, MD.

Nishizawa Y (2001) Glutamate release and neuronal damage in ischemia. Life Sci 69:369-381.

Noh KM, Kim YH, Koh JY (1999) Mediation by membrane protein kinase C of zinc-induced oxidative neuronal injury in mouse cortical cultures. J Neurochem 72:1609-1616.

Paschen W (1996) Glutamate excitotoxicity in transient global cerebral ischemia. Acta Neurobiol Exp (Wars) 56:313-322.

Perez Velazquez JL, Frantseva MV, Carlen PL (1997) In vitro ischemia promotes glutamate-mediated free radical generation and intracellular calcium accumulation in hippocampal pyramidal neurons. J Neurosci 17:9085-9094.

Snider BJ, Choi J, Turetsky DM, Canzoniero LM, Sensi SL, Sheline CT, Wang $\mathrm{X}$, Yu SP, Choi DW (2000) Nitric oxide reduces $\mathrm{Ca}(2+)$ and $\mathrm{Zn}(2+)$ influx through voltage-gated $\mathrm{Ca}(2+)$ channels and reduces $\mathrm{Zn}(2+)$ neurotoxicity. Neuroscience 100:651-661.

Sousa SF, Fernandes PA, Ramos MJ (2005) Farnesyltransferase-new insights into the zinc-coordination sphere paradigm: evidence for a carboxylate-shift mechanism. Biophys J 88:483-494.

St Croix CM, Wasserloos KJ, Dineley KE, Reynolds IJ, Levitan ES, Pitt BR (2002) Nitric oxide-induced changes in intracellular zinc homeostasis are mediated by metallothionein/thionein. Am J Physiol Lung Cell Mol Physiol 282:L185-L192.

Stork CJ, Li YV (2006) Measuring cell viability with membrane impermeable zinc fluorescent indicator. J Neurosci Methods 155:180-186.

Tonder N, Johansen FF, Frederickson CJ, Zimmer J, Diemer NH (1990) Possible role of zinc in the selective degeneration of dentate hilar neurons after cerebral ischemia in the adult rat. Neurosci Lett 109:247-252.

Truong-Tran AQ, Carter J, Ruffin RE, Zalewski PD (2001) The role of zinc in caspase activation and apoptotic cell death. Biometals 14:315-330.

Tsien R, Pozzan T (1989) Measurement of cytosolic free Ca2+ with quin2. Methods Enzymol 172:230-262.

Vallee BL, Falchuk KH (1993) The biochemical basis of zinc physiology. Physiol Rev 73:79-118.

van Lookeren Campagne M, Thibodeaux H, van Bruggen N, Cairns B, Gerlai R, Palmer JT, Williams SP, Lowe DG (1999) Evidence for a protective role of metallothionein-1 in focal cerebral ischemia. Proc Natl Acad Sci USA 96:12870-12875.

Verkhratsky A (2005) Physiology and pathophysiology of the calcium store in the endoplasmic reticulum of neurons. Physiol Rev 85:201-279.

Wei G, Hough CJ, Li Y, Sarvey JM (2004) Characterization of extracellular accumulation of $\mathrm{Zn} 2+$ during ischemia and reperfusion of hippocampus slices in rat. Neuroscience 125:867-877.

White BC, Grossman LI, O’Neil BJ, DeGracia DJ, Neumar RW, Rafols JA, Krause GS (1996) Global brain ischemia and reperfusion. Ann Emerg Med 27:588-594.

Yokoyama M, Koh J, Choi DW (1986) Brief exposure to zinc is toxic to cortical neurons. Neurosci Lett 71:351-355.

Zhang Y, Wang H, Li J, Jimenez DA, Levitan ES, Aizenman E, Rosenberg PA (2004) Peroxynitrite-induced neuronal apoptosis is mediated by intracellular zinc release and 12-lipoxygenase activation. J Neurosci 24:1061610627. 